\title{
Towards a better integration of ecology in palaeoecology: from proxies to indicators, from inference to understanding
}

\author{
Thomas A. Davidson ${ }^{1}$, Helen Bennion ${ }^{2}$, Michael Reid ${ }^{3}$, Carl D. Sayer ${ }^{2} \&$ Thomas \\ Whitmore $^{4}$ \\ ${ }^{1}$ Department of Bioscience and Arctic Research Centre (ARC), Aarhus University, \\ Vejlsøvej 25, 8600 Silkeborg, Denmark \\ ${ }^{2}$ Environmental Change Research Centre, Department of Geography, University College \\ London, Gower Street, London, UK, WC1E 6BT \\ ${ }^{3}$ Riverine Landscapes Research Laboratory, Geography and Planning, University of New \\ England, Armidale, New South Wales, Australia \\ ${ }^{4}$ Deparment of Biological Sciences, University of South Florida St. Petersburg, St. \\ Petersburg, Florida 33701, USA. \\ Co-authors are listed in alphabetical order.
}

keywords: Palaeoecology: Early warning indicators: Transfer functions: Ecology: Proxy

\begin{abstract}
The special issue titled "Putting the Ecology into Palaeoecology" stems from a session with that name that was held at the 2015 International Paleolimnological Association meeting (International Paleolimnology Symposium) in Lanzhou, China. We briefly describe the motivation for the session, and summarise the contributions to this special issue. Additionally, we discuss our perceptions and concerns about the progress, challenges and future directions of palaeolimnology, stressing the importance of meaningful integration of ecological principles and thinking into palaeo-approaches.
\end{abstract}




\section{Introduction}

The subject of this special issue is the integration of ecology into palaeoecology. We see a pressing need to bring more ecological thinking into palaeoecology and a parallel need for contemporary lake ecology to embrace a longer-term perspective. This latter need for a longer-term perspective is increasingly recognised, a fact illustrated by the EU initiative on Long Term Ecosystem Research (LTER). The benefits of studying ecosystems over a number of years stems from the fact that many ecological processes (dispersal, population dynamics, growth, food web dynamics, succession, species extinction) which drive biological change tend to operate over timescales that are greater than the typical length of contemporary aquatic ecological studies (1-3 years), and in many cases might involve decades for change to occur. It is clear, therefore, that palaeoecology has enormous potential to provide this much needed long-term perspective on ecosystem change, but the significance of this contribution rests on a better integration of ecological thinking into palaeo-studies.

The origins of this special issue stem from the recent history of palaeolimnology, in particular the proliferation of quantitative environmental reconstructions from lake sediments based on transfer-function models. The transfer-function approach has many appealing aspects, from a lake-management perspective in particular (Anderson 1997; Bennion et al. 1996) but the generality and usefulness of transfer-function models has been increasingly questioned (Sayer 2001; Velle et al. 2010), with caution actually sounded from the beginning (Fritz et al. 1993). A discussion of the limitations of transferfunctions has been conducted in detail elsewhere (Whitmore et al. 2015), but nevertheless needs to be briefly revisited here as it highlights wider potential issues and challenges for palaeolimnology as a whole. The kernel of the problem is the attempt to infer change in a single chemical/biological/climatic variable from biological communities (e.g. diatoms, chironomids, cladocerans, pollen) almost always shaped by multiple, interacting forces. Thus, at their core, transfer functions are inherently non-ecological. As a consequence we call for a greater consideration of ecological theory in palaeoeoecology and for the development of much more robust, ecologically meaningful models capable of taking multiple structuring variables into account. This would increase the acceptance of palaeoapproaches in general ecological investigations and provide the long-term perspective so desperately needed to inform ecological theory and in turn practical aquatic conservation.

The transfer-function approach emphasises the use of sedimentary remains as proxies, or substitute measures, for other variables of interest. The idea of a proxy has become prevalent, but the term has increasingly lost its meaning through incorrect use. In particular, the term 'multi-proxy' has become common, often with the biological assemblages in cores not being used as a proxy for something else. Here, we stress the need for a continued shift away from seeing biological remains as proxies of something else, and instead call for their use as indicators to track ecological change in ecosystems on the realistic (decadal to centennial) timescales over which change actually occurs in real-world aquatic environments.

Palaeolmnology has been greatly strengthened by studies that consider several lines of biological evidence. The analysis of the remains of several biological groups provides multiple strands of evidence, potentially from different levels of the food-web, and of terrestrial and aquatic origin to provide a much fuller picture of the nature, and 
importantly perhaps even the major causes, of environmental change (Bennion et al. 2015; Sayer et al. 2016). However, the use of multiple biological groups does not, in itself, represent the complete integration of ecology into the palaeo discipline. Multiindicator studies may have the potential to provide an increasingly broad view of ecosystem responses, but we should go further by asking questions such as: can we investigate the ecological processes and even mechanisms that shape biological communities and try to decipher these using a long-term perspective? Echoing previous calls for a better combination of modern ecology and palaeoecology (Smol 1991; Battarbee et al. 2005; Reid and Ogden 2006; Sayer et al. 2010c), we urge palaeolimnologists to combine methods to address key ecological questions and to try to isolate mechanisms of change by combining short and long-term perspectives. We encourage investigations that address a variety of ecological processes such as predation, competition, succession, speciation as well as other topics at the community and landscape levels.

The integration of ecology into palaeoecology to help infer mechanisms of change can be attempted in many ways and can involve using relationships established in contemporary environments to interpret past biological change in a semi-qualitative way (e.g. regression tree models: Davidson et al. 2010). Alternatively core data can be interpreted qualitatively via existing knowledge frameworks in limnology and aquatic ecology to develop understanding of, for example, trophic cascades (Leavitt et al. 1989) and changed seasonality of primary producers (Sayer et al. 2010a). Such approaches aim to get at the nature and causes of ecological change, which contrasts with feeding data into transfer-function models or using ordinations that undoubtedly identify points of change or trends. We urge researchers to explore and test mechanisms that would provide knowledge of direct use to aquatic ecological science and aquatic conservation. It follows that interpretation of sediment-core sequences would benefit immensely from improved understanding of the ecology of species that demonstrate changes in abundance, and greater knowledge about the limnological functioning of the aquatic systems that are being worked upon.

In order to infer changing ecological processes and mechanisms in the long-term and to increase the acceptance and use of palaeo-studies in aquatic ecology and conservation, there is a pressing need to get back to basics, and for palaeoecologists to get involved in community and autoecological studies to better understand species preferences, dynamics (over a range of time scales) and interactions. This need is especially true of groups such as diatoms, ostracods, and chironomids for which there are many palaeo-studies, but comparatively few in contemporary ecological research. Further, so that ecological information can be confidently inferred from sediment assemblages of species, it is crucial that we continue to study taphonomy to understand how assemblages are formed and how well fossil assemblages reflect biocoenoses in space and time. This is a fundamental basic underlying principle of palaeoecology that should never be ignored.

\section{Special issue papers}


This special issue includes 13 papers that address the issues raised above and demonstrate the value of better integration of ecology in palaeoecology. The papers are summarised according to a number of themes.

\section{Taphonomy}

The way in which the living biological community is represented in the sedimentary record is a fundamental issue in palaeolimnology. While this issue is widely recognised and frequently acknowledged, it is less often subject to detailed analysis in field studies. The studies addressing taphonomic processes in sedimentary systems described in this special issue are thus a valuable addition to understanding.

Dalton et al. examined sediment distribution patterns in an Irish humic lake, using a combination of sediment traps and surface sediment samples, to explore the transfer of environmental signals from the water column to lake-sediment records. They identified marked spatial and temporal variation in the deposition of aquatic versus terrestrially derived organic matter and a strong influence of lake-basin position and water depth on a range of parameters including diatom and pigment assemblages, with implications for the interpretation of ecological signals in the sediment record. This study provides an example of how palaeolimnological and contemporary limnological approaches can be integrated through the application of sediment traps, allowing comparisons between contemporary and sedimentary processes such as sinking rates, particle flux and phytoplankton dynamics.

On a similar theme, Maier et al. employed sediment traps to compare whole-year diatom assemblages for a 12-year period with the corresponding diatom record of the annually laminated sediment in a varved boreal lake in Sweden. They observed large inter-annual variability of diatom succession and abundance patterns in the traps driven by seasonal environmental events, such as winter air temperature and/or autumn runoff, as well as the thermal structure of the lake. This variability was well reflected in the varved sediments. The study highlights the need to consider short-term environmental events when interpreting annual sediment signals in relation to climate.

Bishop et al. compared modern survey data with sedimentary remains for a single macrophyte species Najas flexilis. Detailed modern surveys were compared with very highly spatially resolved sampling of surface sediments across three lakes that represent a gradient of modern $N$. flexilis abundance from occasional to absent. The study showed that $N$. flexilis remains are found even where the plant is currently absent, and that the abundance of seeds at an individual point does not reflect the abundance of the plants at the same location. However, many more seeds were found at sites where plants were abundant, whereas fewer were found at sites where plants were less abundant, and fewer still where the plant was currently absent.

Species ecology, habitat preferences

The transfer-function boom drove extensive sampling programmes that yielded abundant distributional information among biological groups with respect to specific water-quality variables. However, less research has been conducted with respect to the broader ecology 
of individual taxa, including habitat preferences, which would better inform ecological interpretations.

Pla et al. synthesised a very large quantity of diatom data from a single Pyrenean lake, identifying variation in species assemblages between, and species preference for, different habitats. They demonstrated that deep-lake sediment samples represent wholelake gamma diversity. The study also showed how $\mathrm{pH}$ reconstructions based on species from the different habitats gave different results and can be explained by the different productivity and thus dissolved inorganic carbon concentration of the habitats, which alters $\mathrm{pH}$.

Prentice et al. integrated macrofossil data from a previous study with new data on testate amoeba from Loch Leven, Scotland, which has a long history of eutrophication. The history of eutrophication-driven change in submerged plants was compared with changes in testate amoeba. The study showed the testate amoeba community to change at the same time as plant macrofossil assemblages. Indicator-species analysis identified certain taxa to be associated with different aquatic vegetation structures reflecting eutrophication-induced change.

Emson et al. reported, rather surprisingly, a strong relationship between the comparatively rare diatom taxa Lemnicola hungarica and Sellaphora saugerresii and the minute floating-leaved species of Lemna (Araceae), which leave scant evidence in lake sediments of their past presence. The investigators examined diatoms in surface sediments of small ponds in Norfolk, England that showed periods of Lemna dominance. Sediment cores from Bodham Rail Pit were examined at high resolution, and these diatom indicators closely tracked known annual abundances of Lemna over a 20-year period. This study disclosed species-specific host preferences of epiphytic diatoms and the potential to use those relationships to assess macrophytes that leave little evidence in sediments. The study would not have been possible without a combination of modern data and high-resolution historic analyses, as well as mindful attention to the importance of examining the ecological significance of rare taxa. This epiphyte/host relationship appears to hold promise for ecological interpretation in a wide range of lake sizes and geographic regions.

\section{Drivers and mechanisms}

Whilst it is not strictly speaking possible to isolate causality with certainty using the palaeo record, it may be possible to isolate the most probable mechanisms of change, or to reduce the plausible hypotheses to one. Pennington (1981) noted, in a classic paper, that only hypotheses that explain all sets of paleolimnological data should be regarded as true. Thus we need to be cautious when inferring causes of change in the long-term, but it is clear that when contemporary ecological and palaeoecological studies are combined, important insights can be made (Sayer et al. 2010c).

Whitmore et al. carried out a palaeolimnological study of sediment cores from seven shallow, subtropical Florida lakes to explore the reasons for diatom successions from Aulacoseira- to fragilarioid-dominated assemblages, typically associated with eutrophication. They concluded that cyanobacteria are responsible for reducing planktonic Aulacoseira in favour of fragilarioid taxa, with the most likely mechanisms being reduced light availability, cyanobacterial allelopathy or other aspects of 
competitive exclusion, while climate warming was not seen as a likely cause of the observed species shifts. This is an important finding as increases in fragilarioid taxa have often been interpreted as statistical noise in paleolimnological reconstructions, whereas it is clear that in subtropical Florida lakes they can indicate a progression to hypereutrophic conditions and dominance of cyanobacteria.

Reid et al. explored the relative influence of local land-use changes and flow regulation as drivers of change in floodplain lakes (billabongs) on a dryland river floodplain in Australia. They found evidence that the impact of drivers varied with hydrological connectivity, whereby the effect of land-use change was greater for more isolated billabongs and the effect of hydrological change was greater for more connected billabongs. Reid et al. attributed this pattern to stronger coupling of isolated billabongs to the local catchment compared to more connected billabongs, which were more strongly coupled to the hydrology of the parent stream. This study demonstrates the potential palaeo-approaches have to disentangle multiple stressor effects and highlights how hydrology and geomorphology can interact to influence the sensitivity of shallow lake ecosystems to specific stressors.

McGowan et al. studied seasonal patterns in epilithic diatom assemblages in the littoral zone of 19 Arctic lakes along a climate gradient in Western Greenland to better understand diatom ecology, and hence inform palaeoecological reconstructions. Complex relationships with water-chemistry gradients were observed with various nutrients (e.g. nitrate-nitrogen and silicate) and alkalinity being the most influential factors, depending on the season and distance from the coast. A novel element of this study is its determination of functional attributes of diatoms through which a greater understanding is gained of how the community is structured differently in spring versus summer. Finally, the knowledge gleaned about species ecology is applied to previously published diatom records to determine whether additional ecological information can be extracted from the sediment record. The use of Epithemia taxa as indicators of nitrogen limitation to infer long-term changes in lake nitrogen cycling is a particularly salient example of the insights gained from contemporary ecological studies.

Wengrat et al. looked at how increases in productivity alter the diversity of diatom assemblages in sediment cores from seven tropical, eutrophic reservoirs in Brazil. The authors provided evidence for a marked decrease in spatial beta-diversity between waterbodies as well as a decrease of alpha-diversity within a site over time, suggesting that eutrophication leads to homogenization of the diatom assemblage. This study serves to illustrate the valuable role of palaeoecology in understanding changes in freshwater biodiversity in response to eutrophication.

Salgado et al. studied modern macrophyte and associated invertebrate communities of Castle Lough, Northern Ireland, and explored how diversity was influenced by spatial heterogeneity of environmental factors. The investigators also examined how plant and invertebrate macrofossil assemblages changed over more than a century in sediment cores from three sub-basins in the lake. The results showed that modern spatial heterogeneity, particularly with respect to water depth, promotes greater diversity because of habitat complexity, but that eutrophication decreased diversity over time and exerted a homogenising effect on communities. This paper demonstrates the importance of combining modern ecological studies with historical approaches to provide 
greater understanding of the factors that influence community structure, and how this is progressively changed by drivers that arise from human influence.

Long-term changes in biodiversity and biological communities

As noted above, palaeolimnology covers timescales which are otherwise out of reach. Other papers in the special issue used this long-term perspective to better understand community dynamics, species interactions, changes in biodiversity and to enhance our understanding of species ecology:

Bennion et al. show how sedimentary macrofossil records can be used to define ecological reference conditions and assess the condition of lakes, and thereby assist in the setting of conservation objectives and management goals. Based on a sound understanding of present-day plant ecology, they interpret the observed general shift towards macrophyte species more typically associated with eutrophic conditions over the last century as a sign that the lakes are on a pathway to complete macrophyte loss such that nutrient load reduction is urgently needed. The study demonstrates the value of using modern macrophyte ecology to interpret historical change.

Boxem et al. analysed the plant macrofossils and pollen from sediment cores of a wetland in Ontario, Canada to identify long-term changes in the aquatic plant community. The study indicates that plant community composition has been impacted by human activities (deforestation, water regulation), with a notable shift from a sedge-dominated wet-meadow wetland to a cattail-dominated system, the latter of which is known to cause loss of ecosystem diversity. The value of such studies for informing restoration strategies is clearly demonstrated. The recommendation is to reintroduce native sedge species that were present prior to catchment disturbance.

\section{Progress, future challenges and research needs}

Despite promising developments for many species groups used in palaeoecology, even very well utilised groups such as diatoms, ostracods, chironomids, and testate amoebae, we still lack sufficient contemporary ecological knowledge. In turn this current lack of knowledge hampers what we can do meaningfully in terms of inferring underlying processes from species compositional patterns.

There remains a large disparity between palaeo and contemporary investigation. Despite a huge growth in diatom-based palaeo studies with ever more elaborate approaches for reconstruction, there has not really been a corresponding growth of diatom ecology studies. Fundamental here is the need for greater knowledge of diatom seasonality, species responses to mixing, light and habitat preferences in terms of substrates, depth zones and the importance of influences from competition and grazing/food-web effects. For example, in the case of diatoms, some studies have looked at diatom seasonality with a view to more informed palaeo-reconstruction of limnological dynamics, climate and species interactions (Bennion et al. 2012; Kirilova et al. 2008; Köster and Pienitz 2006; McQuoid and Hobson 1997; Sayer et al. 2010a) but many more are needed. Such information would be invaluable to the development of more sophisticated palaeolimnological interpretations and to understanding of the long-term response of diatoms. 
Studies on macrophytes have been productive and have shown the potential for increased understanding about ecosystem change (Bennion et al. this issue; Bishop et al. this issue; Boxem et al. this issue; Salgado et al. this issue). For example, studies of plant macro-remains combined with modern studies of seasonality have allowed us to more confidently infer long-term lake seasonality change (Sayer et al. 2010a), changes in plant community structure (Madgwick et al. 2011) and taphonomy (Bishop et al. this issue). In particular, when combined with other groups, such as cladocerans, pigments or diatoms, it is possible to identify the most likely processes and mechanisms driving change in macrophyte abundance, such as shifts from benthic to pelagic production (Davidson et al. 2011) or fish kills (Leavitt et al. 1989; Sayer et al. 2016). This in turn can help to develop our understanding of the mechanisms that control macrophyte distribution on different spatial and temporal scales. Increased understanding about the ecology of individual taxa and their associations with other biological groups can help us move away from using sedimentary assemblages as a proxy for chemical concentration of $\mathrm{H}^{+}$ions or total phosphorus, for example, and towards their use as describers of ecosystem change. This shift from proxies to indicators might seem like semantics, but it represents a different intention towards the use of the sediment record.

The use of a greater range of ecological indicators, numerical methods and replication or multiple cores and multiple site studies (Reid et al. this issue; Salgado et al. this issue; Wengrat et al. this issue) has encouraged researchers to both focus on more ecologically based aspects (such as biodiversity) or to pose more ecological questions (as opposed to environmental history questions) and to test hypotheses generated from contemporary ecology and palaeo studies. These include testing ideas about the nature of alternative stable states and catastrophic change (Hobbs et al. 2012; Ogden 2000; Randsalu-Wendrup et al. 2014; Sayer et al. 2010b), trophic cascades (Jeppesen et al. 2001; Leavitt et al. 1989; Sayer et al. 2016) and patterns of biodiversity change (Davidson et al. 2010, Davidson et al. 2013; Gregory-Eaves and Beisner 2011).

The above examples and many others demonstrate how useful palaeo-approaches are to investigating ecological change, and the potential for addressing and testing ecological theories in general. It is the authors' view that the future of palaeoecology and palaeolimnology as relevant disciplines depends on the palaeo-community embracing the 'ecology' in palaeoecology. Crucial here is gaining an actual understanding of what the presence and abundance of species of different biological groups and their change over seasons, years, decades and centuries, mean for a lake. This is significantly different from looking at patterns of variance in axis 1 scores of a particular species group and simply inferring "change" over time. The latter has been used in the identification of early warning indicators (EWIs) preceding a 'critical transition' (Wang et al. 2012) or regime shifts which reportedly occur when an ecosystem shifts between two alternative equilibria (Scheffer and Carpenter 2003) as suggested in shallow lakes as a response to nutrient-enrichment (Scheffer et al. 1993). Certain patterns of variance are reportedly diagnostic of 'flickering' or 'critical slowing down' which are early warnings of an impending catastrophic shift (Scheffer et al. 2009). This approach, though addressing an interesting and important ecological question, does not integrate ecological or limnological understanding into the study. The identity of the species, their habitat preferences and their ecological significance are not considered but rather patterns in the variance (autocorrelation) alone are used. From a perspective of trying to increase our 
ecological understanding of the processes leading to, for example plant loss and the reductions in biodiversity and ecosystem services (such as carbon storage) that occur in shallow lakes, such studies provide little illumination. Furthermore, even if they are real, it is questionable whether the early warnings could be adequately detected in real time by an environmental manager (Spears et al. 2017).

We propose the use of more meaningful EWIs of loss of resilience or loss of ecological value and change in key ecosystem functions (e.g. carbon processing). Such EWIs should be grounded in well-established mechanisms that can be understood and interpreted by limnologists and lake managers alike. In the case of shallow lakes affected by eutrophication and vulnerable to plant loss, these might include the reduction in the length of the growing season linked to macrophyte species loss (Hilt et al. 2013; Sayer et al. 2010d), more substantial interannual variation in plant abundance (Bayley et al. 2007) and benthic to pelagic shifts in production (Davidson et al. 2011; Vadeboncoeur et al. 2003). The identification and understanding of all of these potential early warnings has been assisted by the long-term perspective that palaeoecological methods bring and is most appropriately addressed by a combination of ecological and palaeoecological methods.

To conclude we call for greater collaboration between ecologists and palaeoecologists, and for a more concerted effort to employ the long-term perspective provided by palaeolimnology to detect mechanisms that lead to ecological degradation and biodiversity loss in aquatic systems. We emphasise the need to shift away from seeing biological remains simply as proxies of something else. In addition, we call for better-integrated studies that address ecosystem function and change in holistic terms, and that test fundamental theoretical ecological questions in the palaeo context. 


\section{References}

Anderson N (1997) Historical changes in epilimnetic phosphorus concentrations in six rural lakes in Northern Ireland. Freshw Biol 38:427-440

Battarbee RW, Anderson NJ, Jeppesen E, Leavitt PR (2005) Combining palaeolimnological and limnological approaches in assessing lake ecosystem response to nutrient reduction. Freshw Biol 50:1772-1780

Bayley S, Creed I, Sass G, Wong A (2007) Frequent regime shifts in trophic states in shallow lakes on the Boreal Plain: Alternative "unstable" states? Limnol Oceanogr 52:2002-2012

Bennion H, Carvalho L, Sayer CD, Simpson GL, Wischnewski J (2012) Identifying from recent sediment records the effects of nutrients and climate on diatom dynamics in Loch Leven. Freshw Biol 57:2015-2029

Bennion H, Davidson TA, Sayer CD, Simpson GL, Rose NL, Sadler JP (2015) Harnessing the potential of the multi-indicator palaeoecological approach: an assessment of the nature and causes of ecological change in a eutrophic shallow lake. Freshw Biol 60:1423-1442

Bennion H, Juggins S, Andersons N (1996) Predicting epilimnetic phosphorus concentrations using an improved diatom-based transfer function and its application to lake eutrophication management. Environ Sci Technol 30:2004-2007

Davidson T, Sayer C, Perrow M, Bramm M, Jeppesen E (2010) The simultaneous inference of zooplanktivorous fish and macrophyte density from sub-fossil cladoceran assemblages: a multivariate regression tree approach. Freshw Biol 55:546-564

Davidson TA, Bennion H, Jeppesen E, Clarke GH, Sayer CD, Morley D, Odgaard BV, Rasmussen P, Rawcliffe R, Salgado J, Simpson GL, Amsinck SL (2011) The role of cladocerans in tracking long-term change in shallow lake trophic status. Hydrobiologia 676:299-315

Davidson TA, Reid MA, Sayer CD, Chilcott S (2013) Palaeolimnological records of shallow lake biodiversity change: exploring the merits of single versus multi-proxy approaches. J Paleolimnol 49:431-446

Fritz S, Kingston J, Engstrom DR (1993) Quantitative trophic reconstruction from sedimentary diatom assemblages: a cautionary tale. Freshw Biol 30:1-23

Gregory-Eaves I, Beisner BE (2011) Palaeolimnological insights for biodiversity science: an emerging field. Freshw Biol 56:2653-2661

Hilt S, Köhler J, Adrian R, Monaghan MT, Sayer CD (2013) Clear, crashing, turbid and back - long-term changes in macrophyte assemblages in a shallow lake. Freshw Biol 58(10):2027-2036

Hobbs WO, Zimmer KD, Thiessen K, Edlund M, Michelutti N, Butler MG, Hanson MA, Carlson T (2012) A 200-year perspective on alternative stable state theory and lake management from a biomanipulated shallow lake. Ecol Appl 22:1483-1496 
Jeppesen E, Leavitt PR, de Meester L, Jensen JP (2001) Functional ecology and palaeolimnology: using cladoceran remains to reconstruct anthropogenic impact. Trends Ecol Evol 16:191-198

Kirilova EP, Bluszcz P, Heiri O, Cremer H, Ohlendorf C, Lotter AF, Zolitschka B (2008) Seasonal and interannual dynamics of diatom assemblages in Sacrower See (NE Germany): a sediment trap study. Hydrobiologia 614:159-170

Köster D, Pienitz R (2006) Seasonal Diatom Variability and Paleolimnological Inferences - A Case Study. J Paleolimnol 35:395-416

Leavitt P, Carpenter S, Kitchell J (1989) Whole-lake experiments: the annual record of fossil pigments and zooplankton. Limnol Oceanogr 34:700-717

Madgwick G, Emson D, Sayer CD, Willby NJ, Rose NL, Jackson MJ, Kelly A (2011) Centennial-scale changes to the aquatic vegetation structure of a shallow eutrophic lake and implications for restoration. Freshw Biol 56:2620-2636

McQuoid MR, Hobson LA (1997) A 91-year record of seasonal and interannual variability of diatoms from laminated sediments in Saanich Inlet, British Columbia. J Plankton Res 19:173-194

Ogden RW (2000) Modern and historical variation in aquatic macrophyte cover of billabongs associated with catchment development. Regul River 16:497-512

Pennington W (1981) Records of a lake's life in time: the sediments. Hydrobiologia 79:197-215

Randsalu-Wendrup L, Conley DJ, Carstensen J, Hansson L-A, Brönmark C, Fritz SC, Choudhary P, Routh J, Hammarlund D (2014) Combining limnology and palaeolimnology to investigate recent regime shifts in a shallow, eutrophic lake. $\mathrm{J}$ Paleolimnol

Reid MA, Ogden RW (2006) Trend, variability or extreme event? The importance of long-term perspectives in river ecology. River Res Appl 22:167-177

Sayer C (2001) Problems with the application of diatom-total phosphorus transfer functions: examples from a shallow English lake. Freshw Biol 46:743-757

Sayer CD, Burgess A, Kari K, Davidson TA, Peglar S, Yang H, Rose NL (2010a) Longterm dynamics of submerged macrophytes and algae in a small and shallow, eutrophic lake: implications for the stability of macrophyte-dominance. Freshw Biol 55:565-583

Sayer CD, Davidson TA, Jones J (2010b) Seasonal dynamics of macrophytes and phytoplankton in shallow lakes: a eutrophication-driven pathway from plants to plankton? . Freshw Biol 55:500-513

Sayer CD, Davidson TA, Jones J, Langdon P. (2010c) Combining contemporary ecology and palaeolimnology to understand shallow lake ecosystem change. Freshw Biol 55:487499

Sayer CD, Davidson TA, Jones JI. (2010d) Seasonal dynamics of macrophytes and phytoplankton in shallow lakes: a eutrophication-driven pathway from plants to plankton? Freshw Biol 55:500-513 
Sayer CD, Davidson TA, Rawcliffe R, Langdon PG, Leavitt PR, Cockerton G, Rose NL, Croft T. (2016) Consequences of fish kills for long-term trophic structure in shallow lakes: implications for theory and restoration. Ecosystems 19:1289-1309

Scheffer M, Bascompte J, Brock WA, Brovkin V, Carpenter SR, Dakos V, Held H, Van Nes EH, Rietkerk M, Sugihara G (2009) Early-warning signals for critical transitions. Nature 461:53-59

Scheffer M, Carpenter S (2003) Catastrophic regime shifts in ecosystems: linking theory to observation. Trends Ecol Evol18:648-656

Scheffer M, Hosper SH, Meijer ML, Moss B, Jeppesen E (1993) Alternative equilibria in shallow lakes. Trends Ecol Evol 8:275-279

Smol JP (1991) Are we building enough bridges between paleolimnology and aquatic ecology? Hydrobiologia 214:201-206

Spears BM, Futter MN, Jeppesen E, Huser BJ, Ives S, Davidson TA, Adrian R, Angeler DG, Burthe SJ, Carvalho L, Daunt F, Gsell AS, Hessen DO, Janssen ABG, Mackay EB, May L, Moorhouse H, Olsen S, Søndergaard M, Woods H, Thackeray SJ (2017) Ecological resilience in lakes and the conjunction fallacy. Nat Ecol Evol 1:1616-1624

Vadeboncoeur Y, Jeppesen E, Vander Zanden MJ, Schierup HH, Christoffersen K, Lodge DM (2003) From Greenland to green lakes: Cultural eutrophication and the loss of benthic pathways in lakes. Limnol Oceanogr 48:1408-1418

Velle G, Brodersen KP, Birks HJB, Willassen E (2010) Midges as quantitative temperature indicator species: Lessons for palaeoecology. The Holocene 20:989-1002

Wang R, Dearing JA, Langdon PG, Zhang E, Yang X, Dakos V, Scheffer M. (2012) Flickering gives early warning signals of a critical transition to a eutrophic lake state. Nature 492:419-422

Whitmore TJ, Lauterman FM, Smith KE, Riedinger-Whitmore MA (2015) Limnetic total phosphorus transfer functions for lake management: considerations about their design, use, and effectiveness. Front Ecol Evol 3:149-147 